\title{
An Experimental Investigation of Structural Fire Behaviour of a Rigid Steel Frame
}

\author{
TAKEO HIRASHIMA ${ }^{1}$, KAZUMA OKUWAKI ${ }^{1}$, XUANSU ZHAO ${ }^{1}$, YUKI SAGAMI ${ }^{2}$ and KOJI TOYODA ${ }^{2}$ \\ ${ }^{1}$ Division of Architecture and Urban Science, Graduate School of Engineering, Chiba University \\ 1-33, Yayoicho, Inage-ku, Chiba 263-8522, Japan \\ ${ }^{2}$ Fire Laboratory, Environmental Engineering Department, General Building Research Corporation \\ 5-8-1, Fujishirodai, Suita, Osaka 565-0873, Japan
}

\begin{abstract}
Some experimental studies have been conducted on structural fire behaviour of steel sub-frames in order to investigate the effects of thermal stress due to the axial restraint from columns to a heated beam on the behaviour of connections, and its influences on the connected beam and robustness of steel frames. However, the object connections were not beam-to-beam connections but beam-to-column connections with fin plates, end plates, and web cleats. This paper discusses, on the basis of experimental results, structural fire behaviour of a rigid steel frame with fully-moment-resisting beam-to-beam connections with splice plates and HSFG bolts, and beam-to-column connections with full penetration welds. The structural behaviour in the test was also analysed with finite element analysis using Bernoulli-Euler beam elements. The test results indicated that the moment-resisting connections in the rigid steel frame have sufficient load-carrying capacity, but failure may occur in the connected beam due to inadequate shear resistance of the beam web in fire. The critical temperature of the steel beam could be approximated on the basis of its inherent resistance at elevated temperature and initial effects, because the thermal stress disappeared at the fire limit stage. This study was also intended to provide experimental data to help understand the fundamental behaviour of rigid steel frames in fire.
\end{abstract}

KEYWORDS: rigid steel frames, load-bearing fire test, structural response, steel temperature distribution, connections, finite element analysis, critical temperature, structural fire engineering

\section{NOMENCLATURE LISTING}

E $\quad$ Young's modulus $\left(\mathrm{N} / \mathrm{mm}^{2}\right)$

$E_{t} \quad$ plastic modulus $\left(\mathrm{N} / \mathrm{mm}^{2}\right)$

$l_{1} \quad$ length from the loading point to the beam end $(\mathrm{m})$

$l_{2} \quad$ length from the loading point to the beam-splice connection (m)

${ }_{j} \bar{M}_{b u} \quad$ design ultimate moment resistance of the beam-splice connection for bolts failure $(\mathrm{kN} \mathrm{m})$

$\bar{M}_{p} \quad$ design full-plastic moment of the beam $(\mathrm{kN} \mathrm{m})$

$n \quad$ shape factor of the stress-strain curve

$P \quad$ each single load on the beam $(\mathrm{kN})$

${ }_{j} \bar{Q}_{b u} \quad$ design ultimate shear resistance of the beam-splice connection for bolts failure $(\mathrm{kN})$

$\bar{Q}_{y} \quad$ design shear resistance of the beam $(\mathrm{kN})$

$T \quad$ steel temperature $\left({ }^{\circ} \mathrm{C}\right)$

$T_{c r} \quad$ critical temperature $\left({ }^{\circ} \mathrm{C}\right)$

Greek

$\alpha \quad$ temperature reduction factor

$\varepsilon \quad$ strain

$\varepsilon_{0} \quad$ yield strain

$\sigma \quad$ stress $\left(\mathrm{N} / \mathrm{mm}^{2}\right)$

$\kappa(T) \quad$ reduction factor for strength of steel

\begin{tabular}{ll}
\multicolumn{2}{l}{ subscripts } \\
$b$ & bolt \\
$e$ & beam end \\
${ }_{j}$ & beam-splice connection \\
${ }_{w}$ & web \\
${ }_{w b}$ & web bolt
\end{tabular}

at temperature $T$ 


\section{INTRODUCTION}

Steel fully-moment-resisting frame buildings have ductility through the development of yielding in their members when they receive severe horizontal loading in the case of a strong earthquake. Such a rigid steel framing system has moment-resisting beam-to-beam connections with splice plates and high strength friction grip (HSFG) bolts, and beam-to-column connections with full penetration welds, and it is often utilized for medium and high-rise buildings in highly seismic regions. The ductility of the rigid steel frames is so high that a simple calculation method [1] based on the limit state design is often used for structural fire safety design of steel structures in Japan. Thermal stress in critical members in a steel structure is assumed to disappear at the fire limit stage, and the critical temperatures of members are calculated against only initial effects or permanent service loads. In the method, there must be ensured not only the ductility of members (e.g., low width thickness ratio), but also the high resistance of connections. Therefore, the connection may have the problem that strength loss at elevated temperature is larger for the HSFG bolts than for the steel plates or the connected beams, and in Japanese regulation of fire safety engineering design for steel structures, beam temperature is limited at $550^{\circ} \mathrm{C}$ because of concern about failure of bolted connections. The regulation is so conservative that a research project on the structural fire performance of beam-to-beam connections was planned in order to modify the regulation. This paper discusses structural fire behaviour of a rigid steel frame with fully-moment-resisting beam-to-beam connections with splice plates and HSFG bolts, and beam-to-column connections with full penetration welds on the basis of experimental results.

In European countries, some experimental studies on structural fire behaviour of steel sub-frames have already been conducted in order to investigate the effects of thermal stress due to the axial restraint from columns to a heated beam on connection behaviour and its influences on the connected beam and robustness of steel frames [2 - 5]. However, the object connections are not beam-to-beam connections but beam-to-column connections with fin plates, end plates, and web cleats. Certainly, these beam-to-column connections are key elements for fire engineering design of steel framed structures and it is more important to understand not only strength but also robustness of the connections in steel frames for advanced structural fire safety design (e.g., taking into account the membrane action of unprotected composed flooring system exposed to fire heating). Meanwhile, a rigid steel frame with moment-resisting beam-tobeam connections may be an excellent frame for supporting an unprotected composed flooring system in case of a fire, but no experimental data are available on the structural fire performance of such a rigid steel frame.

AIJ recommendation for fire resistant design of steel structures [1], which gave an approximation to the critical temperature of a simple plastic collapse model, was a research product on the basis of numerical analysis of rigid steel frames. The validity of the approximation method was not clarified by experimental investigation, and AIJ recommendation did not describe the influence of the temperature distribution and shear failure on the critical temperature of statically indeterminate steel beams. Therefore, the load-bearing fire test was conducted in order to investigate the actual behaviour of the rigid steel frames in fire. The specific motivations of this experimental study were as follows:

(1) to obtain the temperature distribution in a protected rigid steel frame exposed to a compartment fire (single storey fire) and to discuss the influence of the steel temperature at the connections on their heat capacities and thermal conduction to the unheated members;

(2) to reveal the behaviour of moment-resisting beam-to-beam connections with splice plates and HSFG bolts and beam-to-column connections with full penetration welds in fire;

(3) to obtain the deflection and elongation of a heated beam in a rigid steel frame and to discuss the influence of restraint from unheated members to the heated beam on the failure of the beam or connections and development of thermal stress in the frame;

(4) to assess an approximation method of the critical temperatures of statically indeterminate beam with moment-resisting connections in fire;

(5) to compare the test result with that obtained from a numerical finite element (FE) analysis using Bernoulli-Euler beam elements and to check the validity of the FE analysis.

It should be pointed out that the fire test was not for a composite beam as would be the case in practice. This paper discusses fundamental structural behaviour of a rigid steel frame in fire. 


\section{TEST AND ANALYSIS}

\section{Test setup, specimen, and measurement}

Fig. 1 shows the experimental setup. A standard fire was assumed to occur on the first storey of a twostorey sub-frame which was taken to be a part of a whole steel frame building. The sub-frame specimen was composed of both side columns and three beams, and the columns were divided into a lower column on the first storey and an upper column on the second storey. Heated members were the middle beam (exposed to fire on three sides) and the lower columns (exposed to fire on four sides). The role of unheated members, which were the top beam, the bottom beam, and the upper columns, was to restrain thermal elongation of the heated middle beam. The middle beam and its connections were examined for their load bearing (or carrying) capacity in fire. The constant load (each target load was $73.8 \mathrm{kN}$ ) applied to the middle beam was near the design allowable permanent load of the beam. The initial bending moment at the ends of the middle beam before heating was $2 / 3$ the yield moment of the beam. The steel grade of the beams and splice plates was SN400B (in accordance with JIS G-3136: Rolled Steels for Building Structure) whose design yield stress is $235 \mathrm{~N} / \mathrm{mm}^{2}$. The dimensions of the section of the beams were height: $300 \mathrm{~mm}$, width: $150 \mathrm{~mm}$, web thickness: $6.5 \mathrm{~mm}$, flange thickness: $9 \mathrm{~mm}$, and fillet radius: $13 \mathrm{~mm}$. The steel columns were cold-formed SHS (square hollow section) columns whose design yield stress is $295 \mathrm{~N} / \mathrm{mm}^{2}$. The sizes of the section of the columns were widths: $250 \mathrm{~mm}$, thickness: $12 \mathrm{~mm}$, and corner radius: $30 \mathrm{~mm}$. Fig. 2 and Table 1 show the details of the connections. Fig. 2 (a) shows the details of the moment-resisting beam-splice connections. The grade of the HSFG bolt was F10T, and the pre-tension of the high-strength hexagon bolts was in accordance with JIS B 1186 for friction grip joints. The bolt shank diameter was $16 \mathrm{~mm}$, and bolt hole diameter was $17 \mathrm{~mm}$. The thicknesses of the splice plates for the flanges and web were $9 \mathrm{~mm}$ and $6 \mathrm{~mm}$, respectively. All lap joints were double shear. A fully-moment-resisting connection was defined [6] as one whose bearing resistance is more than 1.15 times the plastic moment of the beam. As shown in Fig. 2 (b), the beam-to-column connections were full penetration arc welding connections with through diaphragms. The thickness of the diaphragms was $12 \mathrm{~mm}$, and the groove angle was $45^{\circ}$. Web plates of the beams were connected by fillet weld, and the fillet size was $6.5 \mathrm{~mm}$. Table 2 and Table 3 show Certified Mill Test Reports for SN400B, BCR295 and F10T.

The test was carried out in a loading frame and furnace for horizontal elements at General Building Research Corporation of Japan. The temperature of the furnace was controlled to follow the ISO 834-1 standard fire. The fire protection material of the middle beam and lower columns was a ceramic fibre blanket, with a fire resistance rating of about one hour for a thickness of $12.5 \mathrm{~mm}$. The bottom beam in the furnace was covered more with a protection whose thickness was $100 \mathrm{~mm}$, because the bottom beam was assumed to be an unheated beam. The ALC board that formed the ceiling of the furnace was not structurally connected to the middle beam. The total length of the specimen was $4.7 \mathrm{~m}$ and the total height was $2.4 \mathrm{~m}$. The fire test was conducted in reduced scale (about 1 in 2), due to limitations in the structural fire testing facility. While making the experimental plan, Lim's test report [7] was referred. Constant loads were applied near the mid-span of the middle beam as two point loads, and controlled loads were applied to the top beam in order to cancel the loads against the top beam and to control the constant loads against the middle beam (see Fig. 1). Lehigh mechanisms were used in order to prevent lateral buckling of the middle beam.

As shown in Fig. 1, displacement transducers were placed on the middle beam and the upper columns to measure the beam deflection and the beam elongation. In order to investigate the thermal stress in the frame, strain gages were installed at the two sections of the upper columns, which were not affected by heating. Bending moments at the two sections and shear force of the upper columns were given by the values of these strain gages. Fig. 3 shows the arrangement of thermocouples. In order to capture the temperature distribution in the specimen, 58 Cromel-Almel thermocouples (Type K) were installed in the beams, columns, and connections. Fig. 4 shows the result of the gas temperature distribution in the furnace. Seventeen temperature-time curves measured around the test frame followed the standard fire temperaturetime curve reasonably well. 


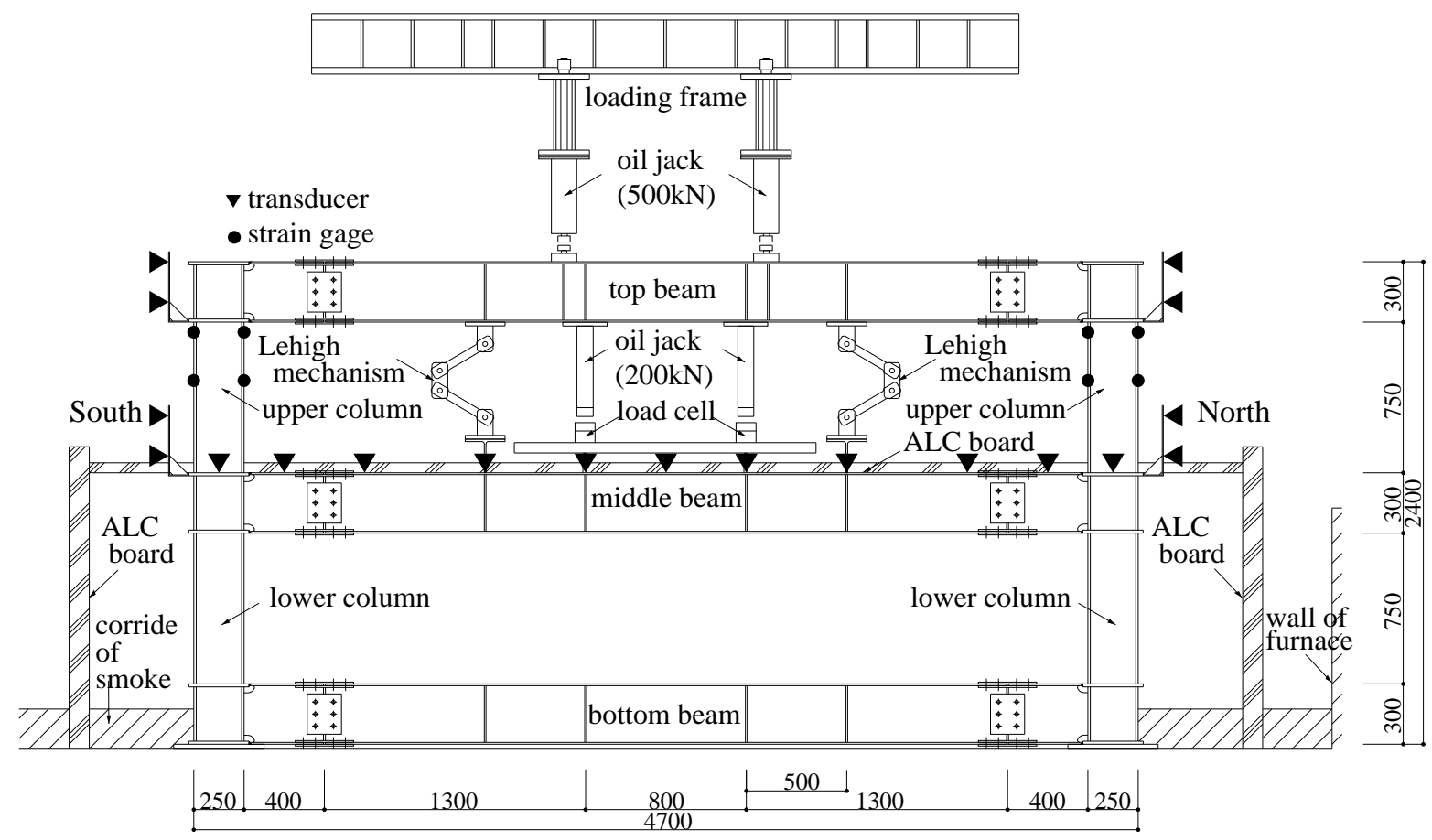

Fig. 1. The test setup. (Unit: $\mathrm{mm}$ )

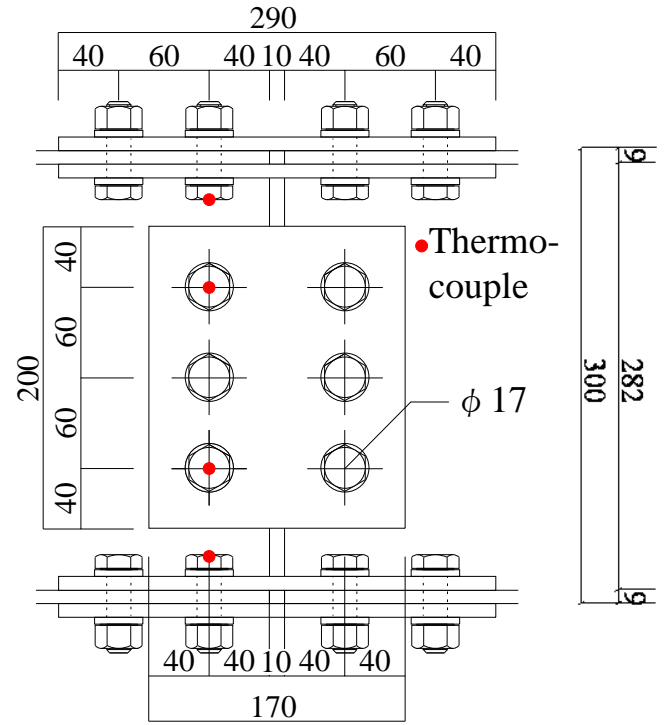

(a) Moment-resisting beam-splice connection.

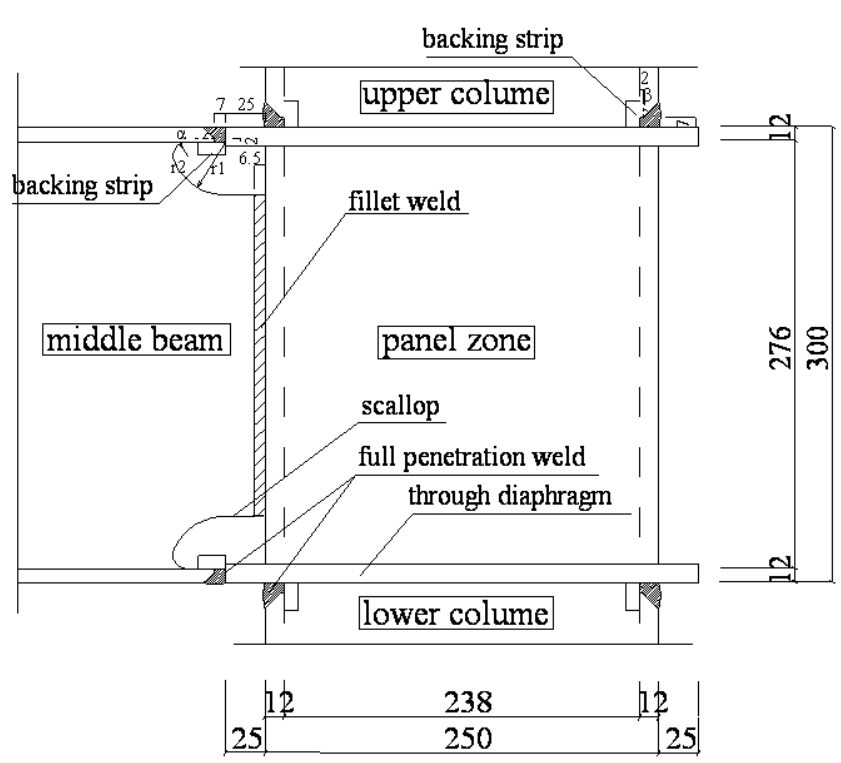

(b) Beam-to-column connection with weld.

Fig. 2. Details of the connections. (Unit: $\mathrm{mm}$ )

Table 1. Details of the connections. (Unit: $\mathrm{mm}$ )

\begin{tabular}{|c|l|l|}
\hline & \multicolumn{1}{|c|}{ Beam-to-beam connection } & \multicolumn{1}{|c|}{ Beam-to-column connection } \\
\hline \hline Flange & $\begin{array}{l}\text { Bolt: F10T-M16x55, Splice plates: SN400B } \\
\text { PL-9x150x290 (out), 2PL-9x60x290 (in) }\end{array}$ & $\begin{array}{l}\text { Full penetration weld with scallop } \\
\text { Groove angle: 45 }\end{array}$, Baking strip: 9x25x150 \\
\hline Web & $\begin{array}{l}\text { Bolt: F10T-M16x50, Splice plates: SN400B } \\
\text { 2PL-6x170x200 }\end{array}$ & $\begin{array}{l}\text { Fillet weld } \\
\text { Fillet size: } 6.5 \mathrm{~mm}\end{array}$ \\
\hline
\end{tabular}


Table 2. Certified Mill Test Reports for SN400B and BCR295.

\begin{tabular}{|c|c|c|c|c|c|c|c|c|c|c|c|c|c|c|c|}
\hline & \multicolumn{3}{|c|}{ Tensile Test } & \multicolumn{12}{|c|}{ Chemical Composition } \\
\hline & $\begin{array}{l}\text { Yield Point } \\
\mathrm{N} / \mathrm{mm}^{2}\end{array}$ & $\begin{array}{c}\text { Tensile Strength } \\
\mathrm{N} / \mathrm{mm}^{2}\end{array}$ & $\begin{array}{c}\text { Elongation } \\
\%\end{array}$ & $\mathrm{C}$ & $\mathrm{Si}$ & $\mathrm{Mn}$ & & $\begin{array}{l}\mathrm{Ni} \\
0\end{array}$ & $\mathrm{Cr}$ & Mo & Ceq & $\begin{array}{l}\mathrm{P} \\
\mathrm{x}\end{array}$ & $\begin{array}{c}S \\
00\end{array}$ & $\mathrm{~V}$ & \begin{tabular}{|c|}
$\mathrm{N}$ \\
$\mathrm{x} 10000$
\end{tabular} \\
\hline SN400B & 308 & 460 & 30 & 11 & 21 & 67 & 0 & 4 & 11 & 1 & 25 & 14 & 7 & 2 & 0 \\
\hline BCR295 & 372 & 454 & 39 & 15 & 2 & 70 & 1 & 1 & 1 & 0 & 27 & 11 & 6 & 0 & 21 \\
\hline
\end{tabular}

Table 3. Certified Mill Test Reports for F10T-M16 x 50.

\begin{tabular}{|c|c|c|c|c|c|c|c|}
\hline \multicolumn{4}{|c|}{ Bolt } & Nut & Washer & Set \\
\hline $\begin{array}{c}\text { Yield Strength } \\
\mathrm{N} / \mathrm{mm}^{2}\end{array}$ & $\begin{array}{c}\text { Tensile Strength } \\
\mathrm{N} / \mathrm{mm}^{2}\end{array}$ & $\begin{array}{c}\text { Elongation } \\
\%\end{array}$ & $\begin{array}{c}\text { Reduction of Area } \\
\%\end{array}$ & $\begin{array}{c}\text { Hardness } \\
\text { HRC }\end{array}$ & $\begin{array}{c}\text { Hardness } \\
\text { HRC }\end{array}$ & $\begin{array}{c}\text { Hardness } \\
\text { HRC }\end{array}$ & Torque Coefficient \\
\hline \hline 1048 & 1095 & 18 & 68 & 34 & 27 & 40 & 0.181 \\
\hline
\end{tabular}

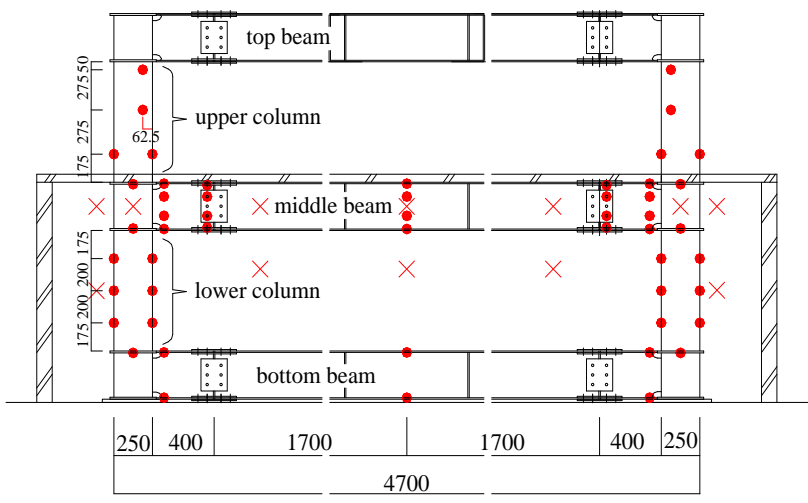

- Thermocouple for measurement of steel temperature

$x$ Thermocouple for measurement of gas temperature

Fig. 3. Arrangement of thermocouples.

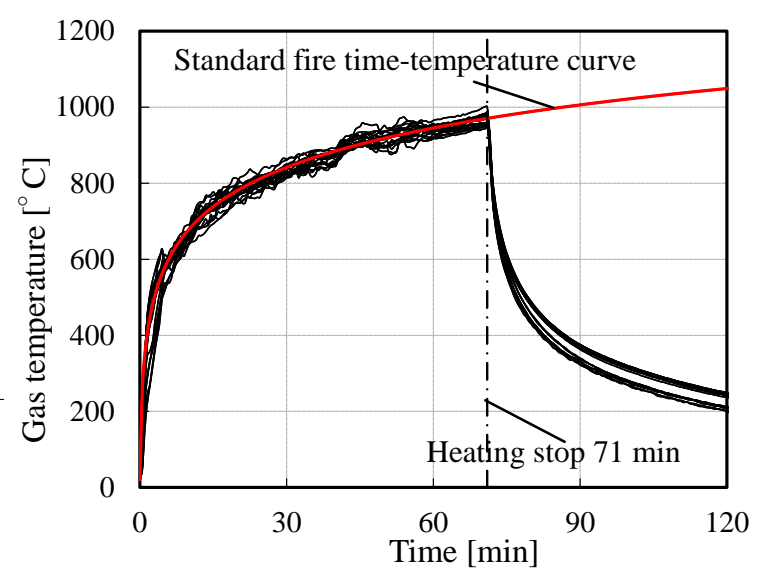

Fig. 4. Gas temperature.

\section{Analytical model and stress-strain curves of the steels at elevated temperatures}

The computational analysis program used originates in a report by Becker and Bresler at the University of California, Berkeley [8], and had been amended by Uesugi et al. at Chiba University [9]. This is an FE analysis using Bernoulli-Euler beam elements, which is capable of modelling the two- and threedimensional behaviour of steel frames subjected to fire, and includes geometrical and material nonlinearities. Fig. 5 shows the half figure of the analytical frame model and the division of steel temperatures for input data for the structural FE analysis. As this analysis program did not take into account bolted connections, the beams and the columns were assumed to be connected by welding and to be perfectly continuous. Thermal analysis was not carried out, and the input data on steel temperatures for structural FE analysis was based on the test result.

The stress-strain relationships for the steels were obtained by elevated-temperature tensile tests in accordance with JIS G-0567. The specimens were cut from the beam flange and the flat part of the column in the same direction as that of hot rolling. Gauge length was $30 \mathrm{~mm}$. The temperatures at the midpoints of specimens were within $\pm 3^{\circ} \mathrm{C}$ of the target temperatures. Velocity of deformation was controlled in a loading machine, and specimen deformation was measured by transducers and amplifiers. The rate of strain was $0.3 \% / \mathrm{min}$ up to $5 \%$ strain. Fig. 6 shows the results of the elevated-temperature tensile tests. Stressstrain curves for use in calculation of the load-bearing fire test of the rigid steel frame were represented by Eq. $1[1,10]$. Table 4 shows the values of Eq. 1.

$$
\sigma=\frac{\left(E-E_{t}\right) \cdot \varepsilon}{\left\{1+\left(\varepsilon / \varepsilon_{0}\right)^{n}\right\}^{\frac{1}{n}}}+\frac{E_{t} \cdot \varepsilon}{\left\{1+(\varepsilon / 0.05)^{2}\right\}^{\frac{1}{2}}}
$$


Table 4. The values of Eq. 1.

\begin{tabular}{|c|c|c|c|c|c|c|c|c|}
\hline \multirow{3}{*}{ Temperature } & \multicolumn{4}{|c|}{$\mathrm{SN} 400 \mathrm{~B}(\mathrm{Beam})$} & \multicolumn{4}{c|}{ BCR295 (Column) } \\
\cline { 2 - 9 } & $\begin{array}{c}E \\
\mathrm{~N} / \mathrm{mm}^{2}\end{array}$ & $\begin{array}{c}E_{t} \\
\mathrm{~N} / \mathrm{mm}^{2}\end{array}$ & $\begin{array}{c}\varepsilon_{0} \\
\mathrm{x} 10^{-6}\end{array}$ & $n$ & $\begin{array}{c}E \\
\mathrm{~N} / \mathrm{mm}^{2}\end{array}$ & $\begin{array}{c}E_{t} \\
\mathrm{~N} / \mathrm{mm}^{2}\end{array}$ & $\begin{array}{c}\varepsilon_{0} \\
\mathrm{x}^{-6}\end{array}$ & $n$ \\
\hline $20^{\circ} \mathrm{C}$ & 208000 & 3526 & 1300 & 2.0 & 208000 & 942.1 & 1900 & 2.0 \\
\hline $300^{\circ} \mathrm{C}$ & 193000 & 6076 & 1300 & 1.4 & 193000 & 2142.2 & 2200 & 1.4 \\
\hline $400^{\circ} \mathrm{C}$ & 191400 & 6343 & 1100 & 1.1 & 174000 & -602.6 & 2400 & 1.1 \\
\hline $500^{\circ} \mathrm{C}$ & 155100 & 2869 & 1400 & 1.1 & 141000 & -607.5 & 1800 & 1.1 \\
\hline $600^{\circ} \mathrm{C}$ & 134200 & 565 & 1000 & 1.1 & 122000 & -262.4 & 1000 & 1.1 \\
\hline $700^{\circ} \mathrm{C}$ & 110000 & -98 & 500 & 1.1 & 100000 & -96.3 & 600 & 1.1 \\
\hline $800^{\circ} \mathrm{C}$ & 85800 & 39 & 400 & 1.1 & 78000 & 72.2 & 400 & 1.1 \\
\hline
\end{tabular}

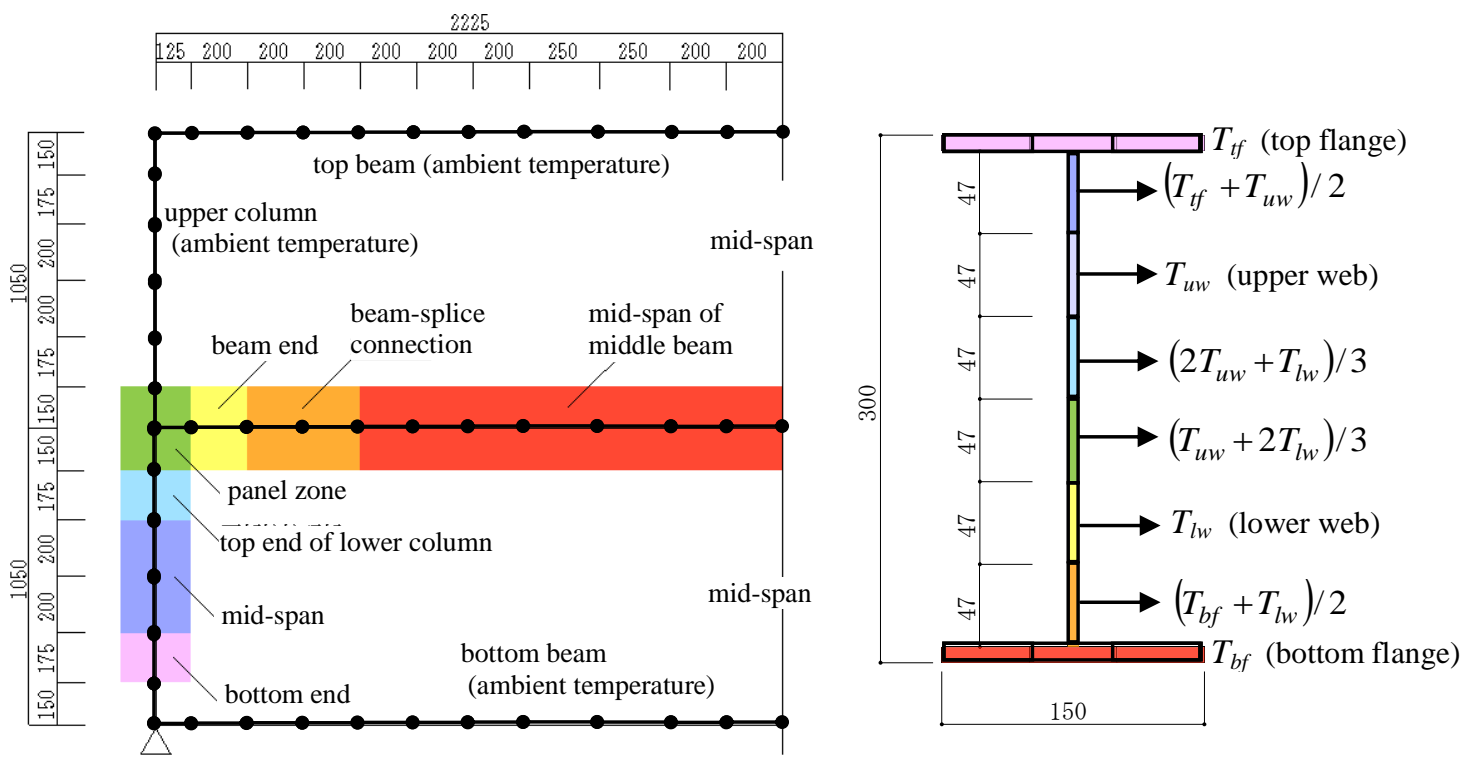

(a) Division of temperatures for the beam elements

(b) Division of temperatures in the beam element

Fig. 5. Half figure of the analytical frame model and the division of steel temperatures.

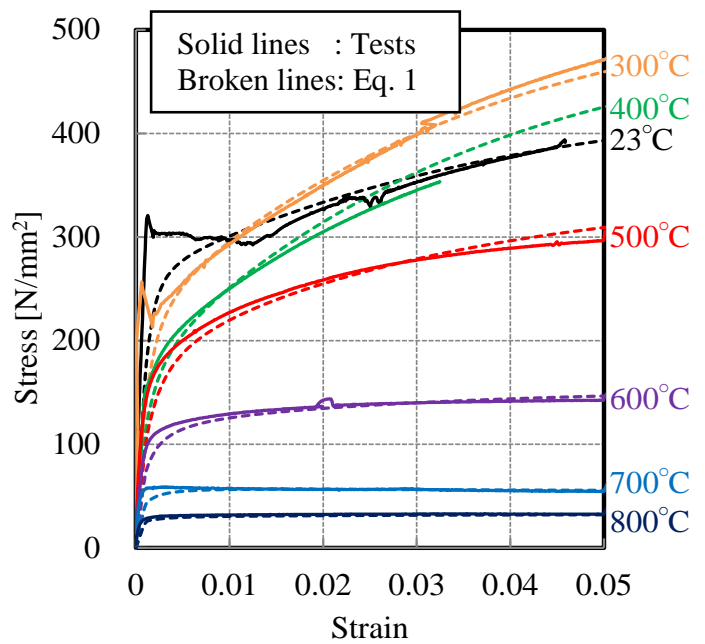

(a) SN400B (Beam)

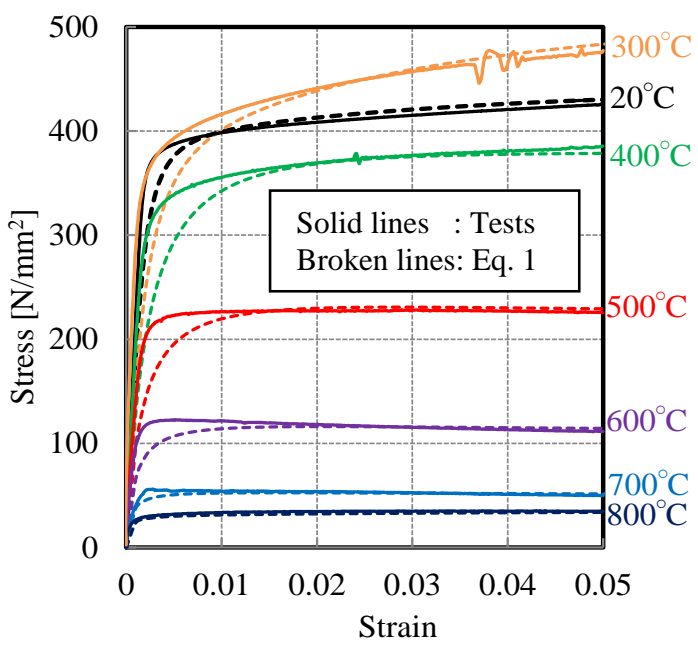

(b) BCR295 (Column)

Fig. 6. Stress-strain relationships for the steels at elevated temperatures. 
As shown in Fig. 6, the calculation models of the stress-strain curve roughly agreed with the elevated tensile test results. The relative thermal elongation of carbon steel for use in the FE analysis is given by Eurocode 3 equations [11].

\section{RESULTS AND DISCUSSION}

\section{Temperature distribution in the steel frame}

Fig. 7 (a), (b), and (c) show the temperatures at the mid-span, the beam-splice connection (north side), and the end (north side) of the middle beam, respectively. The temperatures of the north side at the connection and the end of the beam were almost same as that of the south side. Heating was stopped at 71 min after ignition, when the beam mid-span deflection reached $100 \mathrm{~mm}$. As shown in Fig. 7(a), the temperatures at the bottom flange and the web lower part of the beam mid-span were almost the same and rose to about $580^{\circ} \mathrm{C}$ at $50 \mathrm{~min}$ and above $700^{\circ} \mathrm{C}$ after $70 \mathrm{~min}$. The rising rate of steel temperature decreased from $600^{\circ} \mathrm{C}$, because specific heat capacity of steel gradually increased from $600^{\circ} \mathrm{C}$. The temperature was lower for the top flange than for the bottom flange, because the boundary conditions of heat transfer differed. As shown in Fig. 7(b), the temperature was distinctly lower for the beam-splice connection than for the mid-span of the beam, because moment-resisting beam-splice connections had a relatively high heat capacity. The mean temperature of the connections $\left(377^{\circ} \mathrm{C}\right.$ at $50 \mathrm{~min}$ and $510^{\circ} \mathrm{C}$ at $67.5 \mathrm{~min}$ ) was $71-77 \%$ that for the beam mid-span $\left(528^{\circ} \mathrm{C}\right.$ at $50 \mathrm{~min}$ and $659^{\circ} \mathrm{C}$ at $\left.67.5 \mathrm{~min}\right)$. The time to reach the limiting rate of deflection for flexural elements in accordance with ISO834-1 was $67.5 \mathrm{~min}$. This result was similar to previous report [12] of load-bearing fire tests, imitating the action of continuous beams with beam splice connections. As shown in Fig. 7 (c), the temperature was also lower for the end of the beam than for the mid-span of the beam, because the heat conduction from the beam end to the panel-zone and the unheated upper column occurred at the end due to difference of the temperatures. The temperatures at the end and mid-span of the beam were similar up to $100^{\circ} \mathrm{C}$ at $10 \mathrm{~min}$ after ignition, and subsequently the difference between the two temperatures gradually increased. The mean temperature of the ends $\left(368^{\circ} \mathrm{C}\right.$ at $50 \mathrm{~min}$ and $471{ }^{\circ} \mathrm{C}$ at 67.5 $\min$ ) was about $70 \%$ that for the mid-span. The differences of steel temperatures between the mid-span, the ends of the beam, and the beam-splice connections were considerable. In order to approximate the critical temperature of the beam accurately, the temperature reduction factors should be considered. The temperature reduction factors are shown in Table 5 in the section "Critical temperature of the beam".

Fig. 7 (d) shows the temperatures of the columns and the panel zone (north side). Although the fire protection of the lower column is the same as that for the middle beam, as shown in Fig. 7 (a) and (d), the steel temperature was distinctly lower for the mid-span of the lower column than for the mid-span of the middle beam, and the difference of mean temperatures was above $150^{\circ} \mathrm{C}$ after $50 \mathrm{~min}$. The section factor, which is the ratio of the heated surface area of a steel member to the volume of the member, was lower for the SHS column $\left(0.091 \mathrm{~mm}^{-1}\right)$ than for the I-beam $\left(0.191 \mathrm{~mm}^{-1}\right)$. The temperatures of the lower column were below $500^{\circ} \mathrm{C}$ and the temperature at the bottom of the upper column was about $80^{\circ} \mathrm{C}$ at $70 \mathrm{~min}$. The temperatures at the section where strain gages were installed were below $40^{\circ} \mathrm{C}$ up to 70 min. The temperature was lower for the upper diaphragm $\left(220^{\circ} \mathrm{C}\right.$ at $\left.70 \mathrm{~min}\right)$ than for the lower diaphragm $\left(390^{\circ} \mathrm{C}\right.$ at $70 \mathrm{~min}$ ) of the panel zone.

\section{Observations, connections behaviour, and failure mode}

Fig. 8 (a) shows the global aspect of residual deformation of the frame after the test. The middle beam deflected to a great extent, due to rotation at the connections, shear deformation at the insides of the connections, and bending deflection at the mid-span of the beam. Failure of the beam occurred due to the shear force; i.e., diagonal tension in the beam web adjacent to the connection, and thus a "truss analogy" as a mechanism of shear transfer. Therefore, the resistance of the beam should be related not only to bending resistance but also to shear resistance. For the rigid steel frame, the shear failure of beams may occur in case of a fire, because the shear arm ratio (the ratio of shear span to depth) is smaller for a continuous beam than for a simply supported beam with pin connections (e.g., fin plate connection). Meanwhile, the bending failure mode, which is a plastic collapse of the beam and its connections due to the bending moment, should be also considered, because rotation of the connections was very large. Members other than the middle beam were not deformed to a great extent after the test. 
As shown in Fig. 8 (b), neither beam-to-beam bolted connections nor beam-to-column weld connections failed, and no compressive contact occurred between the bottom-flanges of the connected beams as rotation of the connection develops. Generally, the critical load-carrying mechanism of the moment-resisting beamsplice connection changes from bolt friction mode to bolt bearing in the case of a fire. As shown in Fig. 8 (c), the shear deformation of the bolts developed but the bolts did not fail, because their ductility in shear increased at high temperature. Previous papers $[13,14]$ also reported that bolts in shear did not easily fail at large shear deformations above $500^{\circ} \mathrm{C}$ and their ductility at high temperature may improve the rotational capacity of the bolted connection. For fully-moment-resisting beam-splice connections, deformations due to both bolts in shear and plate yielding developed before plate bearing reached its resistance, and bolts did not fail. In this test, the beam-to-column connections with full penetration welds did not fail either, although the tensile force in the middle beam and its weld connections developed due to thermal contraction of the beam and its restraint by surrounding members during the cooling phase. No cracks occurred in the weld. Failure of full penetration weld connections may not occur because the tensile strength is generally larger for weld metal than for the connected steel. However, it should be pointed out that the performance of the weld connections depends on the welder and welding conditions.

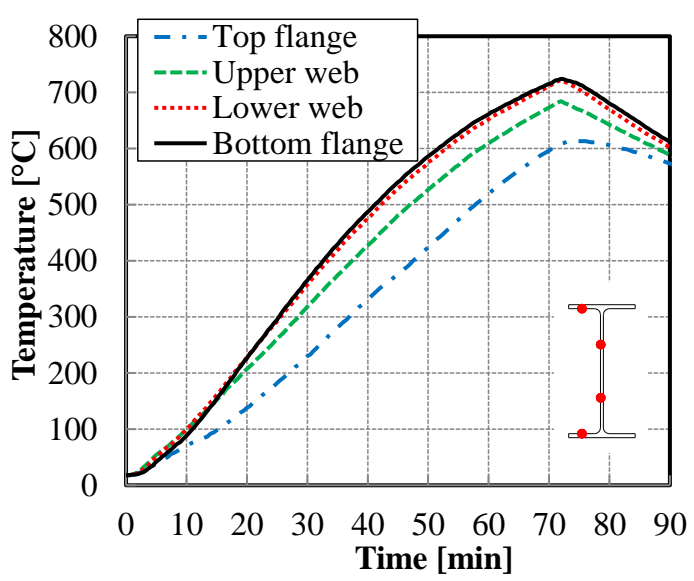

(a) Beam mid-span

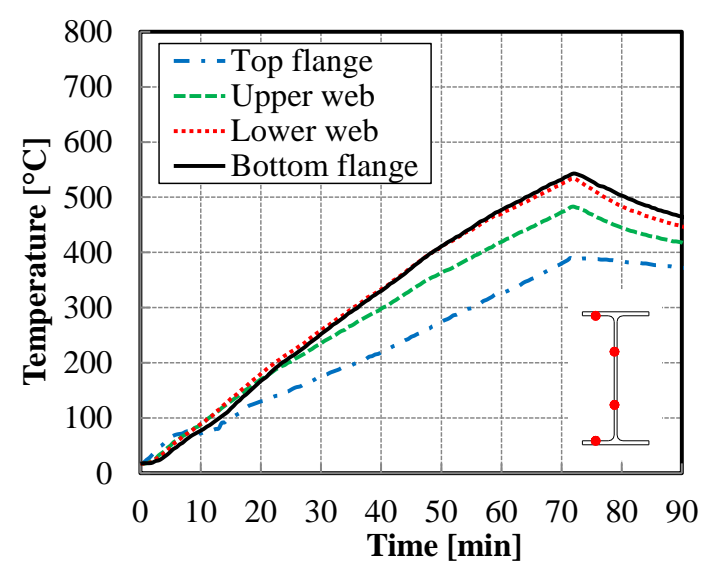

(c) Beam end

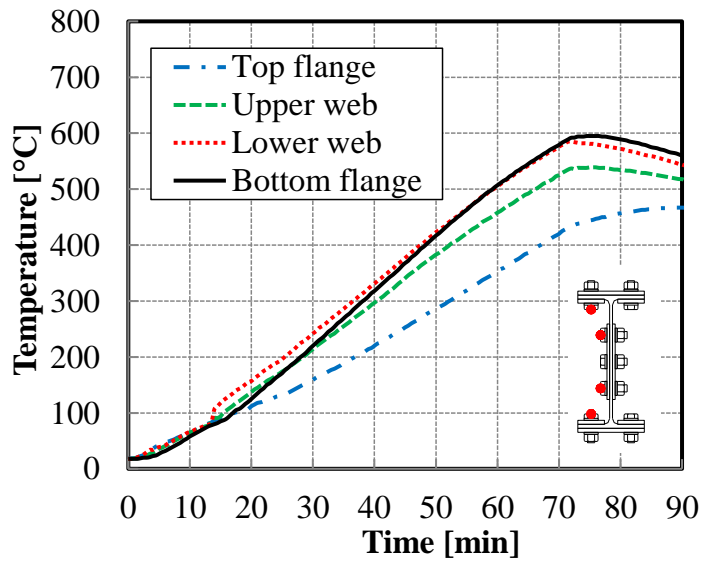

(b) Beam-splice connection

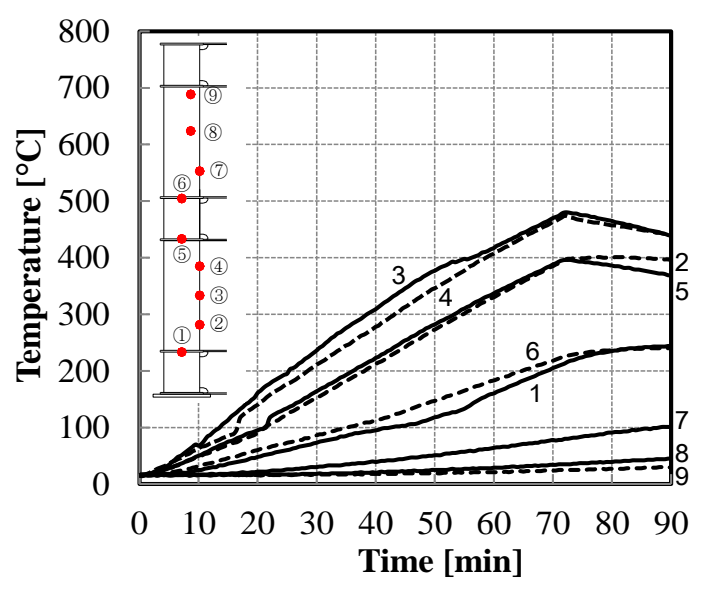

(d) Column

Fig. 7. Steel temperatures. 


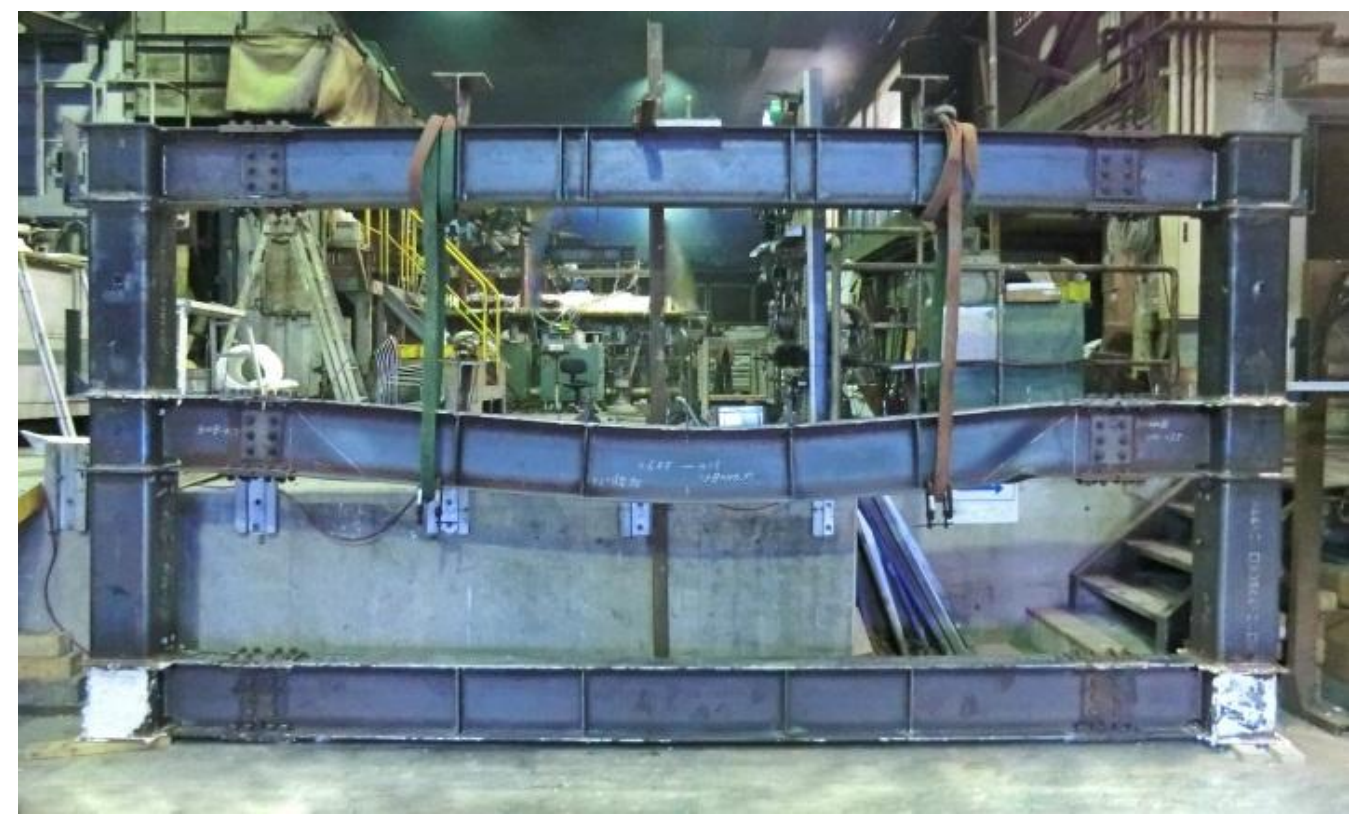

(a) Global aspect of the frame

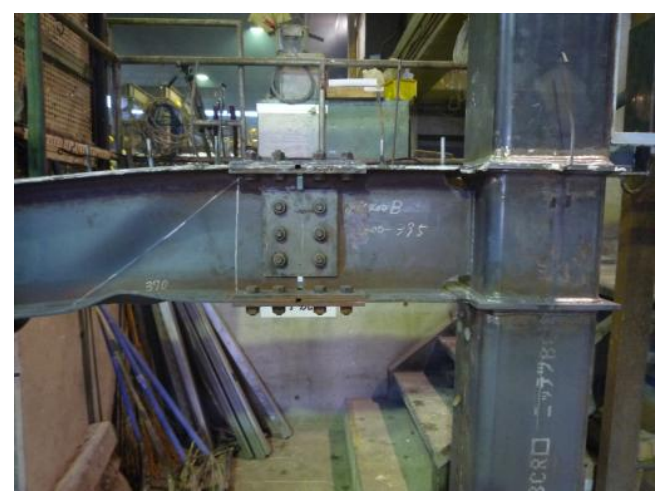

(b) Connections

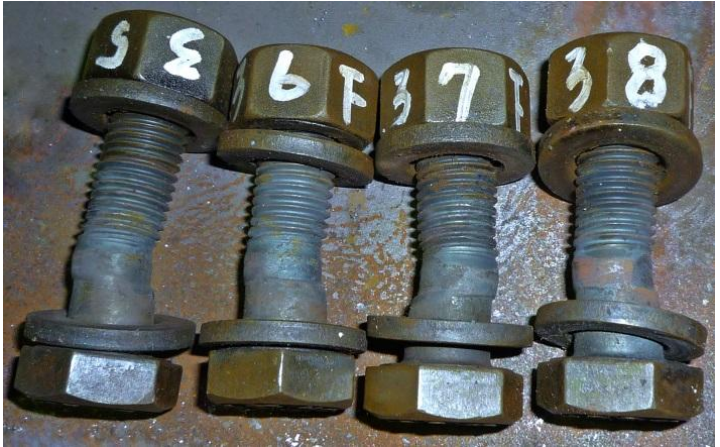

(c) Bottom flange bolts

Fig. 8. Residual deformation of the frame after the test.

\section{Beam deflection, beam elongation, and thermal stress}

Fig. 9 (a) and (b) show the deflection and the rate of deflection (per min) at the mid-span of the middle beam and a comparison of the test result with the result calculated from FE analysis (legend "FEA") using Bernoulli-Euler beam elements. The deflection was the relative vertical displacements between mid-span and ends of the beam. In Fig. 9 (a), the initial deflection is zero, and this does not include deflection due to variation of loading at ambient temperature before heating. The recorded beam mid-span deflection at the target load of $73.8 \mathrm{kN}$ was about $5 \mathrm{~mm}$. During the early stages of the fire, up to $30 \mathrm{~min}$, the beam deflection was very low, because the thermal expansion across the height of the beam, which would normally cause much of the deflection of the beam, was countered by the restraint to rotation at its ends, which applied a hogging moment. Small increases of the deflection occurred suddenly at 33 min and 44 min due to the occurrence of slip between the splices and the connected beams, and the rate of deflection gradually increased after $50 \mathrm{~min}$. The fire resistance time was $67.5 \mathrm{~min}$ (when the mean temperature at the mid-span of beam was $\left.659^{\circ} \mathrm{C}\right)$, which was the time to reach the limiting rate of deflection $\left(L^{2} / 9000 d=7.3\right.$ $\mathrm{mm} / \mathrm{min}, L=4450 \mathrm{~mm}$ : the span of the test specimen, $d=300 \mathrm{~mm}$ : the beam depth) for flexural elements in accordance with ISO834-1. For estimation of the limiting deflection and the limiting rate of deflection, the 
span of the test specimen $L$ was taken to be the length of the beam, which was defined as the distance between the centroids of the columns. It should be pointed out that the limiting values for fire resistant time might be not completely correct, because this was not a test for a simply supported beam. Heating was stopped at $71 \mathrm{~min}$, when the beam mid-span deflection reached $100 \mathrm{~mm}$, and loading was stopped at 73 min (when the mean temperature at mid-span of the beam was $682^{\circ} \mathrm{C}$ ), because the rate of deflection reached $15 \mathrm{~mm} / \mathrm{min}$ and the security of the testing facility was of concern. The specimen might lose its load-bearing capacity around $73 \mathrm{~min}$, although the loading could not be kept up to that point, when the beam exhibited sufficient catenary action. The FE analysis did not take into account the beam-to-beam bolted connection, but the result from FEA agreed with the test result up to about $65 \mathrm{~min}$. This time was close to the fire resistance time $(67.5 \mathrm{~min})$ in accordance with ISO834-1. Subsequently, the rate of deflection was lower for the FEA result than for the test result, because the FE analysis using BernoulliEuler beam elements did not take into account the development of beam deflection due to shear failure. The prediction may need a full non-linear FE analysis using shell elements.

Fig. 10 shows the elongation of the middle beam, which was measured by displacement transducers placed horizontally at the bottom of the upper columns (see Fig. 1). The elongation was thermal elongation of the beam receiving axial restraint by the surrounding members. During the early stages of the fire, up to $50 \mathrm{~min}$ (when the mean temperature at the mid-span of beam is $528^{\circ} \mathrm{C}$ ), the elongation of the beam increased in proportion to the heating time or the temperature of the beam, but the value was considerably lower than the free thermal elongation of the beam. Then the elongation decreased due to the development of deflection of the beam. Fig. 10 also shows the sudden low decreases of the elongation due to the occurrence of slip between the splices and the connected beams, but the elongation might be not affected by the bolted connections very much. The FEA result approximated the whole aspect of the test result for the elongation, but it seemed that slip of the bolted connection was one reason for the difference between the test result and FEA result. It should be pointed out that the FEA result for the elongation did not agree with the test result after $65 \mathrm{~min}$, as in the case of beam deflection.

Fig. 11 shows the variation of the shear force in the upper columns. The shear force in the test was calculated from the values of the strain gages installed at the two sections of the upper column. This was due to thermal elongation of the middle beam and its restraint from the columns. Therefore, Fig. 11 for the variation of the shear force was similar to Fig. 10 for the elongation of the middle beam. The shear force in the upper columns increased during the early stages of the fire, up to $45 \mathrm{~min}$ in the test. After the bending moment at the ends of the column reached the resistance of the column, the shear force in the column decreased due to a reduction of the steel's resistance. Moreover, the shear force decreased sharply due to development of beam deflection after $50 \mathrm{~min}$. The shear force on columns became zero at $72 \mathrm{~min}$, when the beam reached the limit state stage due to its shear or bending ultimate strength at elevated temperature, and then the tensile force in the beam increased and the beam might exhibit catenary action. The FEA result approximated the whole aspect of the test result for the shear force in the columns, as in the case of elongation of the middle beam.

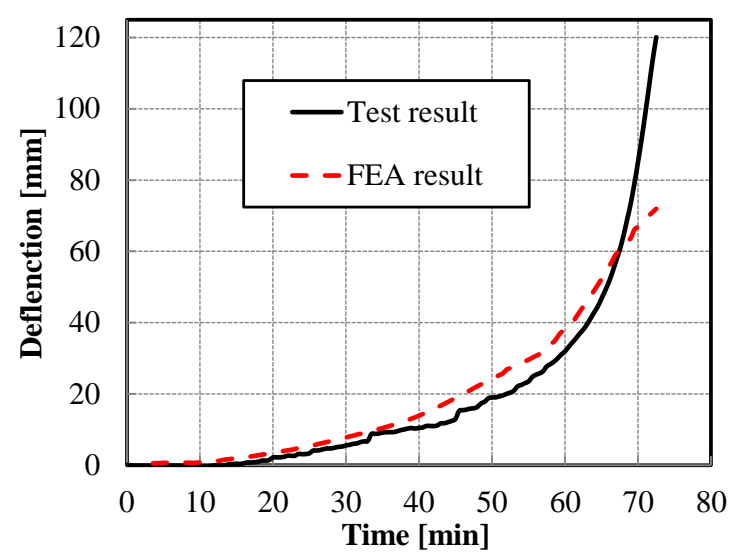

(a) Deflection

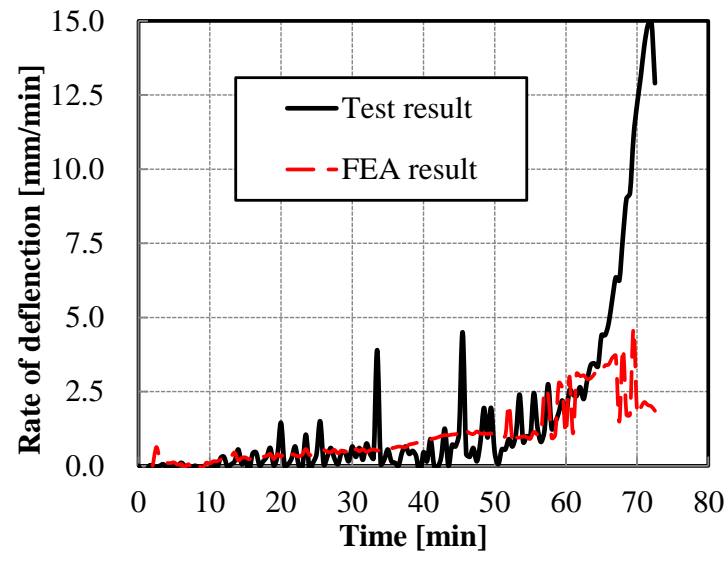

(b) Rate of the deflection

Fig. 9. Deflection at the mid-span of the middle beam. 


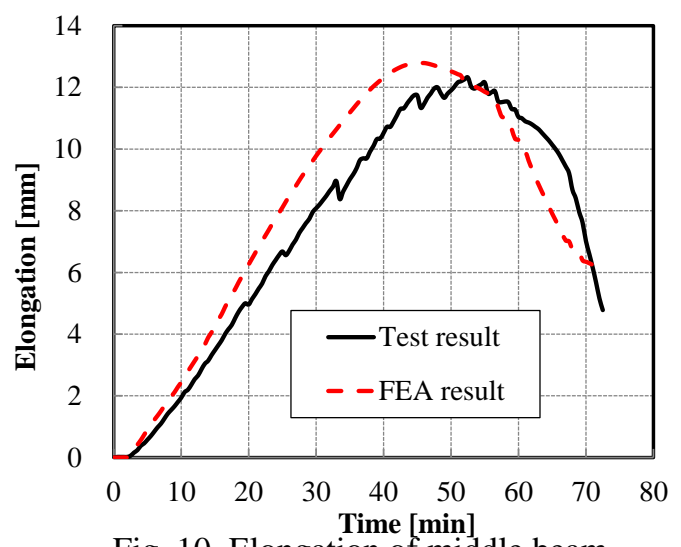

Fig. 10. Elongation of middle beam.

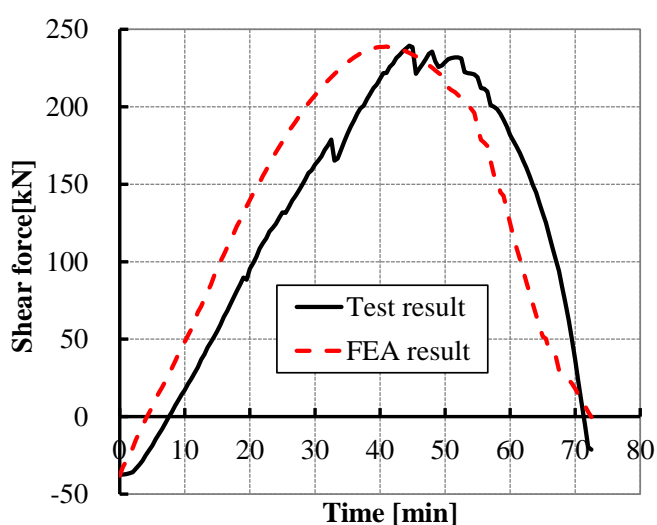

Fig. 11. Shear force in upper columns.

\section{Critical temperature of the beam}

The critical temperatures for continuous steel beams can be approximated on the basis of the theory of simple plastic design $[1,11]$. An approximation to the critical temperature of a simple plastic collapse model was given by AIJ recommendation [1]. This paper also discusses the approximation method for the critical temperature of steel beams with moment-resisting beam-splice connections. The simple plastic collapse model originated in Ozaki-Suzuki's concept [15], which was based on the resistance of the beam and the beam-splice connection in the fire limit state calculated as for an undivided span with three plastic hinges. The resistance of the beam-splice connection was on the bolt failure and was calculated from the strength of the bolts. In this study, the differences of steel temperatures between the mid-span, the ends of the beam, and the beam-splice connections were also taken into consideration [12]. In order to take into account the considerable difference of their temperatures, the critical temperature was defined by the mean temperature of the section at the mid-span of the beam at the fire resistance time or at the limit state stage. Table 5 shows the temperature reduction factors for the beam end, the beam-splice connection, and the beam web, which were the mean temperatures of the sections or the web parts divided by the mean temperature of the section at the mid-span of the beam at $67.5 \mathrm{~min}$, which was the fire resistance time from the test result. The critical temperature of the beam $T_{c r}$ was given by Eq. 2 and this was the minimum critical temperature calculated by Eq. 3 - Eq. 6 . Table 5 also shows the design resistance for the beam and the connection at ambient temperature for calculation of the critical temperature.

$$
\begin{aligned}
& T_{c r}=\min \left(T_{c r 1}, T_{c r 2}, T_{c r 3}, T_{c r 4}\right) \\
& P l_{1}=\bar{M}_{p}\left\{\kappa\left(T_{c r 1}\right)+\kappa\left(\alpha_{e} T_{c r 1}\right)\right\} \\
& P l_{2}=\bar{M}_{p} \cdot \kappa\left(T_{c r 2}\right)+{ }_{j} \bar{M}_{b u} \cdot \kappa_{b}\left(\alpha_{j} T_{c r 2}\right) \\
& P=\bar{Q}_{y} \cdot \kappa\left(\alpha_{w} T_{c r 3}\right) \\
& P={ }_{j} \bar{Q}_{b u} \cdot \kappa_{b}\left(\alpha_{w b} T_{c r 4}\right)
\end{aligned}
$$

On the basis of elevated-temperature tensile tests, the reduction factor for the effective yield strength of the steel used for the beam at elevated temperature was given by Eq. 7. As shown in Fig. 12 (a), the reduction factor for the approximation of the critical temperature agreed with the $1 \%$ proof stress from the tensile tests result. The strength reduction factor of the bolts at elevated temperature was given by Eq. 8 from the results of our previous study [16] on HSFG bolts as shown in Fig. 12 (b). 


$$
\begin{gathered}
\kappa(T)=\left\{\begin{array}{cc}
1.0 & : 20 \leq T \leq 400 \\
2.0-T / 400 & : 400 \leq T \leq 700 \\
1.125-T / 800 & : 700 \leq T \leq 900
\end{array}\right. \\
\kappa_{b}(T)=\left\{\begin{array}{cc}
1.0 & : 20 \leq T \leq 300 \\
1.75-T / 400 & : 300 \leq T \leq 600 \\
1.0-T / 800 & : 600 \leq T \leq 800
\end{array}\right.
\end{gathered}
$$

\begin{tabular}{|c|c|c|c|}
\hline $\begin{array}{l}\text { Collapse } \\
\text { mode }\end{array}$ & $\begin{array}{l}\text { Critical Temperature } \\
T_{c r}\left[{ }^{\circ} \mathrm{C}\right] \text { for: }\end{array}$ & $\begin{array}{l}\text { Temperature reduction } \\
\text { factor } \alpha \text { for: }\end{array}$ & $\begin{array}{l}\text { Design resistance at ambient } \\
\text { temperature }\end{array}$ \\
\hline 1 & $\begin{aligned} T_{c r 1}: & \text { Plastic collapse of the } \\
& \text { continuous beam. }\end{aligned}$ & $\alpha_{e}:$ the beam end. 0.74 & $\begin{aligned} \bar{M}_{p}: & \text { Full-plastic moment of } \\
& \text { the beam. } 127.4 \mathrm{kN} \mathrm{m}\end{aligned}$ \\
\hline 2 & $\begin{array}{l}T_{c r 2}: \text { Plastic collapse at mid-span } \\
\text { of the beam and the beam-splice } \\
\text { connections. }\end{array}$ & $\begin{array}{r}\alpha_{j}: \text { the beam-splice } \\
\text { connection. } 0.77\end{array}$ & $\begin{array}{r}{ }_{j} \bar{M}_{b u} \text { : Ultimate moment resistance } \\
\text { of the connection for the bolts } \\
\text { failure. } 329.7 \mathrm{kN} \mathrm{m} \mathrm{[6]}\end{array}$ \\
\hline 3 & $T_{c r 3}:$ Shear failure of the beam. & $\alpha_{w}:$ the beam web. 1.03 & $\begin{array}{c}\bar{Q}_{y}: \text { Shear resistance for yielding } \\
\text { of the beam web. } 248.7 \mathrm{kN}\end{array}$ \\
\hline 4 & $\begin{aligned} T_{c r 4}: \text { Shear failure of the } \\
\text { beam-splice connection. }\end{aligned}$ & $\alpha_{w b}:$ the web bolt. 0.81 & $\begin{array}{l}{ }_{j} \bar{Q}_{b u}: \text { Ultimate shear resistance for } \\
\text { failure of the web bolts. } 723.0 \mathrm{kN}\end{array}$ \\
\hline
\end{tabular}

Table 5. Temperature reduction factor and resistance for calculation of the critical temperature.

Note: Load $P: 73.8 \mathrm{kN}$, Length $l_{1}: 1.7 \mathrm{~m}$, Length $l_{2}: 1.3 \mathrm{~m}$ (see Fig. 1)

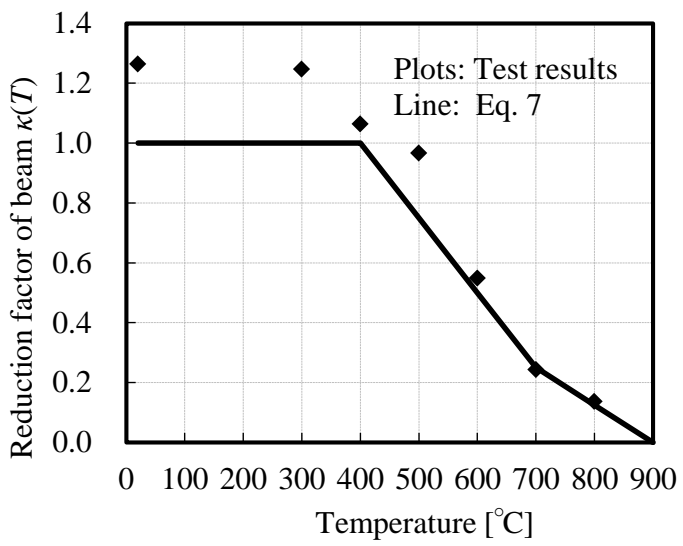

(a) $\mathrm{SN} 400 \mathrm{~B}$ (beam)

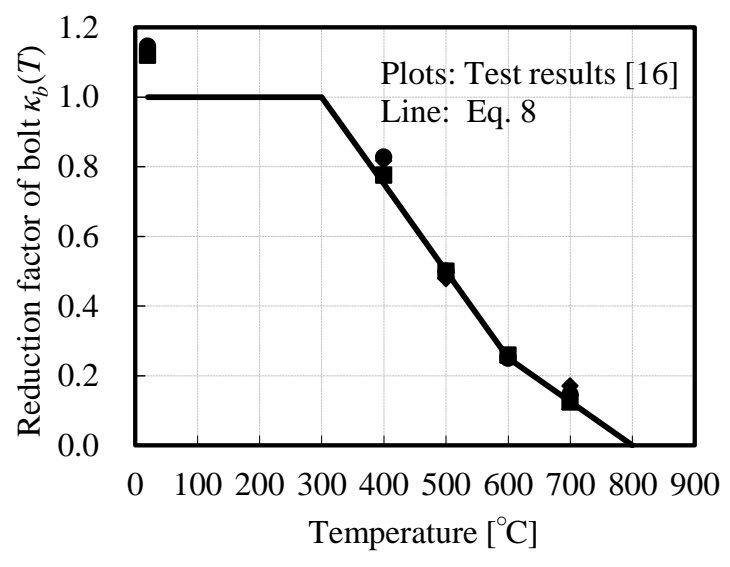

(b) F10T (bolt)

Fig. 12. Reduction factor for the strength of the materials.

Table 6 shows critical temperature and the collapse modes of the beams. The failure mode for the test was determined from the deformation of the specimens after the test (see Fig. 8). The result for the simple plastic collapse model approximately agreed with the test result. The difference in critical temperatures between the test result and the result of the simple calculation was $4{ }^{\circ} \mathrm{C}$, and the collapse mode was the same. This indicated that the critical temperature for the steel beam in a rigid frame can be approximated on the basis of its inherent resistance at elevated temperature and initial effects, because the thermal stress disappeared at the fire limit stage. 
Table 6. The critical temperature of the beam with the beam-splice connections.

\begin{tabular}{|c|c|c|c|c|c|}
\hline Test result & Calculation result $T_{c r}$ & $T_{c r 1}$ & $T_{c r 2}$ & $T_{c r 3}$ & $T_{c r 4}$ \\
\hline \multirow{2}{*}{$\begin{array}{c}\text { Shear failure } \\
\text { of the beam }\end{array}$} & \multirow{2}{*}{$\begin{array}{c}\text { Shear failure } \\
\text { of the beam } T_{c r 3}\end{array}$} & \multicolumn{2}{|c|}{ Bending failure of: } & \multicolumn{2}{|c|}{ Shear failure of: } \\
\cline { 3 - 6 } & & beam & beam and connections & beam & connection \\
\hline $659^{\circ} \mathrm{C}$ & $663{ }^{\circ} \mathrm{C}$ & $695^{\circ} \mathrm{C}$ & $688^{\circ} \mathrm{C}$ & $663{ }^{\circ} \mathrm{C}$ & $813^{\circ} \mathrm{C}$ \\
\hline
\end{tabular}

Notice: These temperatures were the mean temperatures of the section at the mid-span of the beam.

\section{CONCLUSIONS}

This paper has presented structural behaviour results of a load-bearing fire test on a rigid steel frame with connections. This fire test was intended to provide experimental data to help understand the fundamental structural responses of rigid steel frames in fire. The main conclusions were:

(1) Temperature distribution: The difference of steel temperatures between the centre, the ends of the beam, and the beam-splice connections was considerable. The mean temperature of the beam-splice connections was $71-77 \%$ of that of the beam mid-span. The mean temperature of the ends was about $70 \%$ that of the mid-span.

(2) Neither the full-moment-resisting beam-splice connection nor the full penetration weld connection failed, although a large beam mid-span deflection developed during the heating phase and the tensile force in the heated beam developed due to thermal contraction of the beam and its restraint from the surrounding members during the cooling phase.

(3) The beam deflection was very low during the early stages of the fire, because the thermal expansion across the height of the beam was countered by the restraint to rotation at its ends, which applied a hogging moment. The beam deflection gradually increased above $500^{\circ} \mathrm{C}$, and ultimately shear failure of the beam occurred. Therefore, the resistance of the beam should be related not only to bending resistance but also to shear resistance. For the rigid steel frame, the shear failure of beams may occur in the case of a fire, because the shear arm ratio is shorter for a continuous beam than for a simply supported beam with pin connections.

(4) The shear force in the columns increased during the early stages of fire due to thermal elongation of the heated beam and its restraint by the columns. Then the shear force decreased due to degradation of the column and the development of beam deflection, and ultimately, it became zero when the beam reached the limit state stage due to its shear or bending ultimate strength at elevated temperature.

(5) The difference in critical temperatures between the test result and the result of the simple calculation was $4^{\circ} \mathrm{C}$, and the collapse mode was the same. The critical temperature for the steel beam in a rigid frame was approximated on the basis of its inherent resistance at elevated temperature and initial effects, because the thermal stress disappeared at the fire limit stage.

(6) The influence of the slip of the beam-splice connection on the behaviour of the frame in fire was not very large. The result of a finite element analysis using Bernoulli-Euler beam elements approximately agreed with the test result before the occurrence of shear failure of the beam.

\section{AKNOWLEDGEMENTS}

This work was supported by JSPS KAKENHI Grant Number 23246101. The authors would like to thank Prof. Minehiro Nishiyama and Prof. Kazunori Harada at Kyoto University for giving us advice in the meeting of JSPS KAKENHI. The authors would like to acknowledge Toa-rika Co., Ltd for producing the specimen. 


\section{REFERENCES}

[1] Architectural Institute of Japan, "Recommendation for fire resistant design of steel structures", 1st edition 1999, 2nd edition 2008. (in Japanese)

[2] Liu, T.C.H., Fahad, M.K., and Davies, J.M., Experimental investigation of behaviour of axially restrained steel beams in fire, Journal of Constructional Steel Research 58, 2002, pp. 1211-1230, http://dx.doi.org/10.1016/S0143-974X(01)00062-1

[3] Wald, F., Simoes da Silva, L., Moore, D., Lennon, T., Chladna, M., Santiago, A., Benes, M., and Borges, L., Experimental behaviour of a steel structure under natural fire, Fire Safety Journal 41, 2006, pp. 509-522, http://dx.doi.org/10.1016/j.firesaf.2006.05.006

[4] Santiago A, Simoes da Silva L., Vaz, G., Vila Real P., and Gameiro, L.A., Experimental investigation of the behaviour of a steel sub-frame under a natural fire, Steel and Composite Structures, Vol. 8, No. 3, 2008, pp. 243-264

[5] Wang, Y.C., Dai, X.H., and Bailey, C.G, An experimental study of relative structural fire behaviour and robustness of different types of steel joint in restrained steel frames, Journal of Constructional Steel Research 67, 2011, pp. 1149-1163, http://dx.doi.org/10.1016/j.jcsr.2011.02.008

[6] Architectural Institute of Japan, Recommendation for design of connections in steel structures, 2001. (in Japanese)

[7] Lim, S., Ota, S., Sakaguchi, A., Tanaka, Y., Tasaka, S., Tani, M., Harada, K., and Nishiyama, M., Experimental study on fire-resistance of reinforced concrete frames with column-beam connection, Part 1: Outline, Summaries of Technical Papers of Annual Meeting, Architectural Institute of Japan, A-2, 2011, pp. 21-22

[8] Becker, J., Bresler, B., FIRES-RC--- A Computer Program for the Fire Response of Structure --Reinforced Concrete Frames, Report No.UCB FRG74-3, University of California Berkeley, 1974

[9] Li, Y., Lin, H., Hirashima, T., Uesugi, H., and Wakamatsu, T., An analytical method of deflection behavior concerning three-dimensional steel frame exposed to fire which takes account of the thermal expansion of a floor slab, International Journal for Fire Science and Technology, Vol. 24, No. 4, Center for Fire Science and Technology, Tokyo University of Science, 2005, pp. 211-236

[10] Richard, R.M and Abbott, B.J., Versatile Elastic-Plastic Stress-Strain Formula, EM4 Technical Note, 1975, pp. 511-515

[11] CEN, EN 1993-1-2. Eurocode 3: Design of steel structures Part 1-2: General rules - Structural fire design, British standards Institution, 2005

[12] Hirashima, T., Toyoda, K., Yatagai, A., Esaki, Y., Tasaka, S., Yoshida, M., Masuda, H. and Harada, K., Experimental Study on Fire Resistance of H-shaped Steel Beams with High Strength Bolted Joints, J. Struct. Constr. Eng., AIJ, Vol.75 No.658, 2010, pp. 2257-2265 (in Japanese), http://dx.doi.org/10.3130/aijs.75.2257

[13] Hirashima T. and Uesugi H., "Experimental Study on Shear Strength of Friction-Type HighTension Bolted Joints at Elevated Temperature", Proceedings of the 6th Asia-Oceania Symposium on Fire Science and Technology, Daegu, Korea, 272-284, 2004.

[14] Hongxia Y., Burgess I.W., Davison J.B. and Plank R.J, "Experimental investigation of the behaviour of fin plate connections in fire", Proceedings of ICSCS 2007, 541-548, 2007.

[15] Ozaki, F. and Suzuki, H., Ultimate temperatures of steel frames with high strength bolted beam joints subjected to fire, J. Struct. Constr. Eng., AIJ, No.547, 2001, pp. 207-214 (in Japanese)

[16] Hirashima, T., Hamada, N., Ozaki, F., Ave, T. and Uesugi, H., Experimental Study on Shear Deformation behavior of High Strength Bolts at Elevated Temperature, J. Struct. Constr. Eng., $A I J$, No.621, 2007, pp.175-180 (in Japanese) 